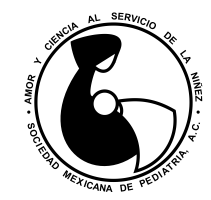

Revista Mexicana de
EDITORIAL

Vol. 86, No. 4 • Julio-Agosto 2019

pp 133-137

Recibido: 31/08/2019

Aceptado: $31 / 08 / 2019$

dx.doi.org/10.35366/SP194A

\title{
Situación actual del sarampión en México y en el mundo
}

\author{
Iván de Jesús Vargas-Almanza, ${ }^{1}$ Ranferi Aragón-Nogales, ${ }^{1}$ María Guadalupe Miranda-Novales ${ }^{2, *}$ \\ ${ }^{1}$ Residente de Infectología Pediátrica. UMAE Hospital de Pediatría "Dr. Silvestre Frenk Freund", \\ Centro Médico Nacional Siglo XXI; ${ }^{2}$ Unidad de Investigación en Análisis y Síntesis de la Evidencia. \\ Coordinación de Investigación en Salud, Instituto Mexicano del Seguro Social, México.
}

\section{INTRODUCCIÓN}

El sarampión es una enfermedad viral aguda, reconocida desde hace más de 2,000 años; fue hasta 1846 , posterior a las observaciones de Panum en las Islas Feroe, que se comprobó que la enfermedad era contagiosa. En 1954, Enders y Peebles aislaron el virus por primera vez en el laboratorio. La enfermedad es causada por un virus del género Morbillivirus de la familia Paramyxoviridae. El único hospedero natural es el hombre, aunque se han reportado casos de infección en monos. ${ }^{1}$ El sarampión se transmite por contacto directo con gotitas de Flügge y la incidencia máxima de la enfermedad se observa a finales de invierno y primavera. ${ }^{1,2}$ Se considera altamente contagiosa. La enfermedad se caracteriza por fiebre, tos, coriza y conjuntivitis, seguida de una erupción maculopapular que comienza en la cara y se extiende de forma cefalocaudal y centrífuga. Durante el periodo prodrómico, puede estar presente un enantema patognomónico en la cara interna del carrillo y a nivel del segundo molar superior, descritas por Henry Koplik a finales del siglo XIX como pequeñas manchas irregulares eritematosas con punto blanquecino (manchas de Koplik). ${ }^{1-3}$ Presenta un periodo de incubación de siete a 21 días, en promedio de 10 días. La transmisibilidad se presenta cuatro días antes y cuatro días después de comenzar el exantema. El exantema dura de cuatro a siete días y posteriormente ocurre descamación.
Las complicaciones del sarampión, que incluyen otitis media, bronconeumonía, laringotraqueobronquitis (crup) y diarrea son más comunes en niños pequeños y hospederos con alguna condición de inmunocompromiso. La encefalitis aguda, que a menudo resulta en daño cerebral permanente, sucede en aproximadamente uno de cada 1,000 casos. En la era postvacunal, las muertes asociadas con sarampión han ocurrido principalmente como resultado de complicaciones respiratorias y neurológicas de hasta 3 de cada 1,000 casos reportados en los Estados Unidos de Norteamérica (EUA). Las tasas de letalidad aumentan en menores de cinco años, así como en pacientes inmunocomprometidos (incluidos niños con leucemia, infección por el virus de inmunodeficiencia humana [VIH], desnutrición severa y deficiencia de vitamina A). A veces, la erupción característica no se desarrolla en pacientes con alguna condición de inmunocompromiso. ${ }^{1}$

\section{RESURGIMIENTO DEL SARAMPIÓN}

Previo a la era de la vacunación de la población de manera sistematizada, se observaban epidemias de cada dos a cinco años, con duración de 3.4 meses aproximadamente. Aunque se dispone de una vacuna eficaz de virus vivos atenuados desde 1963, el sarampión continúa siendo una enfermedad con alta morbimortalidad, sobre todo en países en vías de desarrollo o donde no se ha logrado una adecuada cobertura de vacunación.

\footnotetext{
* Correspondencia: MGMN, guadalupe.mirandan@imss.gob.mx

Conflicto de intereses: Los autores declaran que no tienen.

Citar como: Vargas-Almanza IJ, Aragón-Nogales R, Miranda-Novales MG. Situación actual del sarampión en México y en el mundo. Rev Mex Pediatr 2019; 86(4):133-137.

[Current status of measles in Mexico and worldwide]
} 
Se estima que desde su introducción, los casos de sarampión en los EUA disminuyeron hasta en $99 \% .{ }^{2}$ En ese país, a finales de los años 80 y hasta 1991, se observó un aumento de los casos reportados derivado de la disminución en la tasa de vacunación $;{ }^{1}$ para el año 2000, el sarampión se consideró como enfermedad eliminada. Sin embargo, esta situación ha cambiado en los últimos años, ya que se han presentado varios brotes. En el primer semestre de 2008 se reportaron 131 casos y, desde entonces hasta el 2019, el total de casos ascendió a 2,089, incluyendo el resonado brote en el parque de diversiones Disneylandia en el estado de California en $2015 .{ }^{4}$ Se considera alarmante la situación actual en ese país, ya que hasta la primera semana de septiembre de 2019 se han reportado casos en 31 de los 50 estados que conforman la Unión Americana, contabilizando 1,241 casos de sarampión, lo que representa la mayor cantidad de casos notificados en los EUA desde 1992. De estos individuos, 124 fueron hospitalizados y 64 sufrieron complicaciones como neumonía y encefalitis. Siendo notable que más de $75 \%$ de los casos de este año están vinculados a brotes en Nueva York. ${ }^{5}$ Por fortuna, recientemente se anunció que los brotes habían finalizado en ese estado gracias a las acciones de control.

Fuera de los EUA, la situación es igual de preocupante; desde 2006 los reportes de casos de sarampión no habían sido tan altos como en lo que va de estos primeros seis meses del año. Se han reportado casi tres veces más casos hasta mayo de 2019, que en este mismo periodo del año pasado. Los países que más han reportado casos en lo que va del año son: República Democrática del Congo, Madagascar y Ucrania.

Para el periodo del 1 de enero al 31 de julio de 2019, 182 países notificaron 364,808 casos de sarampión a la Organización Mundial de la Salud (OMS). Para este mismo periodo del año pasado, se habían reportado 129,239 casos en 181 países. Hasta el momento según la OMS, la región de África ha registrado un aumento de $900 \%$, la región de Europa de $120 \%$, la región del Mediterráneo Oriental de 50\%, la región del Pacífico Occidental 230\%; mientras que en la región de Asia Sudoriental y en la región de las Américas registraron una disminución de $15 \%$ en los casos notificados. De manera preocupante, se estima que a nivel mundial sólo se informan menos de uno de cada 10 casos.

Los brotes que afectan a una mayor población se reportan en países con baja cobertura de vacunación. Sin embargo, se describen brotes prolongados en países con alta tasa de vacunación, esto derivado de la heterogeneidad en la cobertura de vacunación, entre las comunidades, áreas geográficas y entre los distintos grupos etarios. No hay que dejar de mencionar que la creciente ola de los movimientos "antivacunas" ha venido a recrudecer el aumento de casos. Las razones por las cuales las personas no se vacunan varían significativamente entre las comunidades y los propios países, donde se incluyen: falta de acceso a servicios de salud o vacunación de calidad, conflictos y desplazamientos, información errónea sobre las vacunas o poca conciencia sobre la necesidad de vacunar.

En la actualidad se cuenta con vacunas altamente efectivas contra sarampión. Se requiere de dos dosis de vacuna para prevenir el sarampión casi al 100\%. Asimismo, se debe mantener una cobertura mayor a 95\% para garantizar que el sarampión no se propague. No obstante, según los datos de cobertura de la OMS y UNICEF publicados en julio de 2019, 86\% de los niños recibió la primera dosis de la vacuna contra el sarampión y $69 \%$ la segunda. ${ }^{6}$

Para la región de las Américas, la Organización Panamericana de la Salud (OPS) ha reportado desde el 1 de enero y hasta el 7 de agosto de 2019 un total de 2,927 casos confirmados de sarampión, incluyendo una muerte. En 2018, se notificó la mayor proporción de casos confirmados en la Región de las Américas en Brasil y Venezuela; mientras que en 2019 la mayoría de los casos confirmados han sido reportados por EUA $(40 \%)$ y Brasil $(36 \%)^{7}$

\section{EL SARAMPIÓN EN MÉXICO}

Las primeras descripciones documentadas del sarampión en nuestro país fueron realizadas por el Dr. M Rodríguez Balda en Mapimí, Durango, durante la epidemia de 1825; posteriormente durante el brote registrado en el estado de Veracruz en 1927-1928, el Dr. A Hernández Mejía realizó una magistral descripción de la enfermedad. ${ }^{8}$

En 1989-1990 se reportó en nuestro país la última epidemia de sarampión que ha vivido México. En 1989 se registraron 20,381 casos con una tasa de 24.2 por 100 mil habitantes; en 1990 fueron 68,782 casos con una tasa de 82.5 y un total de 189 brotes que provocaron 5,899 defunciones; los estados más afectados fueron Veracruz, Oaxaca, Jalisco y Sinaloa. ${ }^{9}$

En México, se inició la aplicación de la vacuna contra sarampión tipo Schwarz en 1970 y en 1978 se cambió la cepa Schwarz por la Edmonston Zagreb, ${ }^{10} \mathrm{y}$ a partir de 1998 se sustituye la vacuna antisarampión monovalente por la vacuna tripe viral que incluye además rubéola y parotiditis. En el año 2000 se inicia la 
aplicación de la vacuna sarampión-rubéola (SR) para niños mayores de 10 años y adultos que no hayan sido vacunados, con esquema incompleto o desconocido. En 2008 se realiza la campaña nacional de vacunación masiva contra el sarampión y la rubéola en la población de 19 años a 29 años de edad, para la erradicación de la rubéola y el síndrome de rubéola congénita. El último caso de sarampión autóctono en nuestro país se registró en 1995.

En el periodo de 2000 a 2019 se han identificado 185 casos importados o asociados a importación. ${ }^{11}$ En el año 2019, en México hasta el día 3 de septiembre de 2019, se habían reportado 16 casos confirmados de sarampión; el primer caso se reportó en el mes de febrero, posteriormente un caso en mayo, cinco casos en julio y nueve para el mes de agosto. Las edades de estos casos varían de los cuatro meses de edad hasta los 54 años. En el caso de los niños, todos son menores de cinco años: cuatro meses, 10 meses, 11 meses, un año, dos años y cuatro años; en los adultos, la edad fluctúa de 18 a 54 años. Del total de los casos, se registró que 10/16 no contaban con antecedente vacunal, los menores de uno y dos años ya habían recibido su primera dosis, un paciente de 27 años recibió dos dosis y dos pacientes recibieron tres dosis; en uno de los casos se desconoce el antecedente. Los estados en donde se han reportado son los siguientes: Quintana Roo (cinco casos), Estado de México (cuatro casos), Chihuahua (tres casos), San Luis Potosí (un caso), Nuevo León (un caso), Guerrero (un caso) y Guanajuato (un caso). Se han catalogado como importados cuatro de ellos, nueve asociados con importación y tres (en el momento de la escritura de este documento) aún estaban en investigación. Es importante destacar que ninguno de los casos reportados ha sido considerado como autóctono, pero aún se mantienen en vigilancia epidemiológica los contactos de los casos confirmados en el mes de agosto, considerando que en caso de contagio aún pueden encontrarse en periodo de incubación próximos a desarrollar las manifestaciones clínicas.

En síntesis, en lo que va del año, el número de casos reportados se triplicó al compararse con el total del año pasado. Asimismo, es importante señalar que los casos confirmados en México forman parte de los grupos vulnerables, es decir, se encuentran descritos entre grupos con falta de esquemas de inmunizaciones (reportado en 62\%), ser menores de cinco años (43\%), realizar viajes internacionales, formar parte de una cadena de transmisión, o bien, ser personal de salud o profesionales en contacto con áreas turísticas o de transporte. Por último, es de destacar que en siete de estos casos el genotipo identificado fue D8 y en dos casos fue B3, por lo que las regiones de donde provienen corresponden a Europa y África, respectivamente. Lo anterior coincide con lo reportado en otras regiones de América. ${ }^{12}$

\section{VIGILANCIA EPIDEMIOLÓGICA DEL SARAMPIÓN}

En 2001, fue presentada la iniciativa contra el sarampión y la rubéola, en la cual participan la Cruz Roja de los EUA, la Fundación pro Naciones Unidas, los Centros para el Control y para el Control y Prevención de Enfermedades (CDC) de EUA, la UNICEF y la OMS. Ésta tiene como compromiso lograr que ningún niño muera de sarampión o nazca con síndrome de rubéola congénita. Así, los objetivos son ayudar a los países a planificar, financiar y medir los esfuerzos dirigidos a terminar con el sarampión y la rubéola. ${ }^{6}$

La región de las Américas es un claro ejemplo, a nivel mundial, de la importancia de las estrategias de eliminación del sarampión, logrando la interrupción de la transmisión endémica en 2002. En 2016 la OPS/OMS declaró a la región de las Américas libre de sarampión, por lo que resulta preocupante el incremento de casos en los últimos meses en esta región y, por supuesto, en el resto del mundo. ${ }^{13}$ En este punto, es importante recordar que cuando una enfermedad se declara eliminada no quiere decir que ha dejado de existir, simplemente significa que, en esa área en específico, ya no hay circulación del patógeno. De esta forma, los casos importados son siempre una amenaza. Ahora bien, un país ya no se considera libre de sarampión cuando la misma cepa del virus ha estado circulando por más de 12 meses seguidos. Mientras que cuando una enfermedad en particular se elimina en todo el mundo, se considera erradicada. A la fecha, sólo una enfermedad infecciosa se considera erradicada, la viruela. El último caso de viruela silvestre ocurrió en Somalia en 1977.

Sin lugar a dudas, la educación en la población, particularmente en el personal responsable de la salud, es indispensable para la identificación de los pacientes afectados. Desde 1993 se estableció el sistema de vigilancia epidemiológica de enfermedades prevenibles por vacunación con el objetivo de lograr una detección oportuna y establecer las acciones a seguir en cada nivel de atención. ${ }^{14}$ Gran parte de los médicos que actualmente están ejerciendo su profesión no han presenciado un caso de sarampión, por lo que es probable que no tengan la experiencia suficiente para identificar, confirmar o para descartar esta enfermedad. Por lo cual es necesario tener en cuenta que debe existir una alta sospecha 
Figura 1:

Inmunización contra el sarampión en México (porcentaje de niños entre 12 y 23 meses de edad).

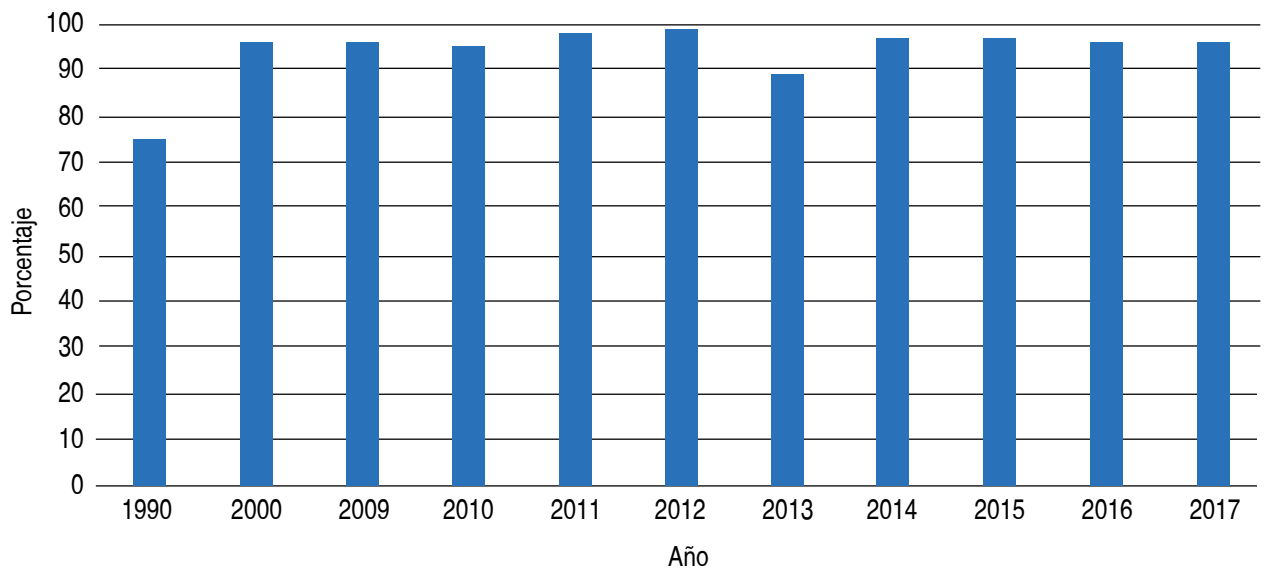

Fuente: Indicadores del desarrollo mundial con datos de WHO/UNICEF. https://datos.bancomundial.org en pacientes que cumplan con la definición operacional de un caso probable de sarampión: cualquier persona que, sin importar la edad, presenta un exantema maculopapular febril más uno de los siguientes signos o síntomas: tos, coriza, conjuntivitis o adenomegalias (retroauriculares, occipitales o cervicales).

Ante un caso probable se debe notificar de forma inmediata en las primeras 24 horas, realizar los estudios de confirmación e iniciar el estudio epidemiológico. En un lapso no mayor de 48 horas se debe tomar muestra de sangre para la determinación de IgM y reacción en cadena de la polimerasa en tiempo real (RT-PCR) en exudado faríngeo, a fin de ser procesados en un laboratorio de referencia. ${ }^{14}$

Desde 2015 la OPS/OMS actualizaron recomendaciones que deben seguir todos los países miembros para reducir la transmisión del virus. Las recomendaciones incluyen lograr coberturas de vacunación homogéneas superiores a $95 \%$ para las primeras dos dosis de la vacuna triple viral. ${ }^{7}$ En 2018 , los 10 países que reportaron la mayor tasa de incidencia de casos de sarampión registraron una cobertura con la primera dosis de sarampión desde 46 a 98\%. Los países que incrementaron su cobertura vacunal aún cuentan con población de riesgo por las tasas bajas de vacunación en años anteriores. México, en 2017, reportó a la OMS cobertura de 79\% para la primera dosis de triple viral y $62 \%$ para la segunda dosis, por lo que nos clasifica como un país de riesgo para la adquisición de la enfermedad. ${ }^{15}$ De acuerdo con los datos registrados en el Banco Mundial, la cobertura de la primera dosis no ha descendido a menos de $89 \%$ entre 2000 y 2017 (Figura 1). ${ }^{16}$

Otra recomendación es la identificación y vacunación a población de riesgo, donde se incluyen aquéllos en quie- nes no se logra documentar antecedente de inmunización o estado serológico, personal de salud, personal que trabaja en transporte y turismo, así como viajeros internacionales. Ante la presencia de brotes, los lactantes de seis a 12 meses se consideran también población de riesgo. ${ }^{14}$

Se deben alertar los sitios donde hay un alto flujo migratorio, como es el caso de zonas turísticas o fronterizas que puedan propiciar la importación del virus. La mayoría de los casos reportados en México en este año se encontraban en ciudades con estas características, como en los estados fronterizos con EUA, en donde se han reportado brotes durante este año. ${ }^{7}$

Todos los servicios de salud deben fortalecer la vigilancia epidemiológica para brindar una respuesta rápida ante casos probables y limitar la transmisión de forma temprana. En el caso de presentarse brotes y en un caso probable que no se logre confirmar por laboratorio, pero exista nexo epidemiológico, se iniciarán las medidas como si se tratara de un caso confirmado. En caso de realizar algún viaje a zonas endémicas y no se logre documentar antecedente de vacunación, se deberá vacunar a todo mayor de seis meses al menos dos semanas previas antes del viaje. ${ }^{15}$

\section{CONCLUSIÓN Y RECOMENDACIONES}

Los casos reportados de sarampión a nivel mundial hasta agosto de 2019, superan el total de reportados con respecto a 2018. Al ser una enfermedad prevenible por vacunación, se requiere incrementar y mantener la cobertura mayor de $95 \%$ en toda la población, reforzar la vigilancia epidemiológica y realizar la notificación inmediata. La notificación se deberá realizar al encontrarnos con un paciente que cumpla con la definición de caso probable (de acuerdo con los signos y síntomas), 
con elevada sospecha, en quienes no están inmunizados o desconocen su estado de inmunización, en sujetos que hayan realizado un viaje 21 días previos a zonas que reportan brotes, o bien, que se encuentren en zonas turísticas o de alto flujo migratorio. Hay que considerar, de acuerdo con los casos reportados hasta el momento, que el estar vacunado no elimina la posibilidad de la enfermedad ante un cuadro clínico compatible.

\section{REFERENCIAS}

1. Gershon AA. Measles virus. In: Mandell, Douglas and Bennett's. Principles and practice of infectious diseases. 8th ed. Canada: Elsevier-Saunders; 2015. pp. 1967-1973.

2. American Academy of Pediatrics. Measles. In: Kimberlin DW, Brady MT, Jackson MA, Long SS, eds. Red book: 2015 Report of the Committe on Infectious Diseases. 30th ed. United States of America. American Academy of Pediatrics; 2015. pp. 535-547.

3. Emerson $\mathrm{H}$. Panum on measles: observations made during the epidemic of measles on the Faroe Islands in the year 1846 (A translation from the Danish). Am J Public Health Nations Health. 1940; 30(10): 1245-1246.

4. Situación Epidemiológica del Brote de Sarampión en Estados Unidos de América y Detección de un Caso Importado en México. Aviso Epidemiológico. CONAVE /01/2015 /SARAMPIÓN. 16 de enero de 2015. [Fecha de acceso 30 de agosto de 2019] Disponible en: http://www.epidemiologia.salud.gob.mx/doctos/avisos/2015/ sarampion/20150116-avisoepidemiologicosarampion.pdf

5. Centers for Disease Control and Prevention. Measles cases and outbreaks. [Fecha de acceso 6 de septiembre de 2019] Disponible en: https://www.cdc.gov/measles/cases-outbreaks.html/

6. World Health Organization. New measles surveillance data from WHO. [Fecha de acceso 6 de septiembre, 2019] Disponible en: https://www.who.int/immunization/newsroom/new-measles-dataaugust-2019/en/
7. Pan American Health Organization/World Health Organization. Epidemiological update: measles. 7 August 2019. Washington, D.C. [Fecha de acceso 30 de agosto del 2019] Disponible en: https://www.paho.org/hq/index.php?option=com_ docman\&view=download\&category_slug=measles2204\&alias=49586-7-august -2019 -measles-epidemiologicalupdate- 1 \&ltemid $=270$ \&lang=en

8. Carrada-Bravo T, Velázquez-Diaz G. El impacto del sarampión en México. Sal Pub Mex. 1980; 22: 359-408.

9. Ferreira-Guerrero E, Montesano R, Ruiz-Matus C. Panorama epidemiológico del sarampión en México. Gac Méd Méx. 1996; 132(1): 97-100.

10. Santos JI. El Programa Nacional de Vacunación: orgullo de México. Rev Fac Med UNAM. 2002; 45(3): 142-153.

11. Situación Epidemiológica de Sarampión. Aviso Epidemiológico CONAVE/01/2019/SARAMPION 15 de febrero del 2019. [Fecha de acceso 30 de agosto de 2019] Disponible en: https://www.gob. $\mathrm{mx}>\mathrm{cms}$, attachment , file > AE-Sarampion-15022019

12. Dirección General de Epidemiología. Casos confirmados de sarampión. [Fecha de acceso 5 de septiembre de 2019] Disponible en: https://www.gob.mx/salud/documentos/casos-confirmadospor-sarampion-2019

13. Centers for Disease Control and Prevention. Manual for the surveillance of vaccine-preventable diseases. Centers for Disease Control and Prevention, Atlanta, GA, Measles. 2008. [fecha de acceso 30 de agosto de 2019] Disponible en: https://www.cdc. gov/vaccines/pubs/surv-manual/chpt07-measles.html

14. Dirección General de Epidemiología. Manual de procedimientos estandarizados para la vigilancia epidemiológica de las enfermedades prevenibles por vacunación. México. Septiembre, 2018. [Fecha de acceso 6 de septiembre de 2019] Disponible en: http://187.191.75.115/gobmx/salud/documentos/manuales/35_ Manual_VE_EPV.pdf

15. IM Coverage. Ais.paho.org. [fecha de acceso 6 de septiembre de 2019] Disponible en: http://ais.paho.org/imm/IM_JRF_ COVERAGE.asp

16. Datos de libre acceso del Banco Mundial. [fecha de acceso 9 de septiembre de 2019] Disponible en: https://datos.bancomundial.org 